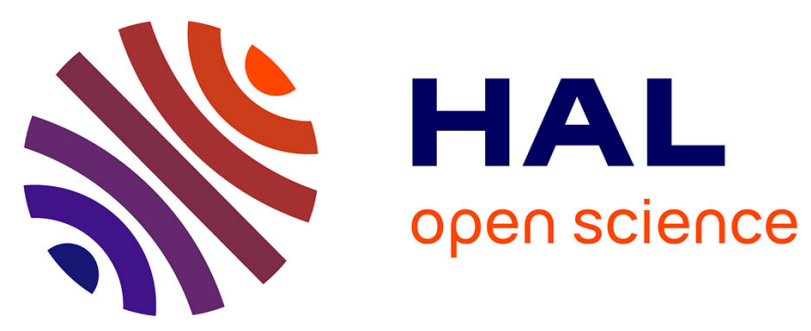

\title{
Detection of sand grains blown by Titan surface winds with the DraGMet/EFIELD sensor on Dragonfly
} Audrey Chatain, Alice Le Gall, Michel Hamelin, Jean-Jacques Berthelier, Ralph D. Lorenz, Rafik Hassen-Khodja, Jean-Pierre Lebreton, Grégoire Déprez

\section{To cite this version:}

Audrey Chatain, Alice Le Gall, Michel Hamelin, Jean-Jacques Berthelier, Ralph D. Lorenz, et al.. Detection of sand grains blown by Titan surface winds with the DraGMet/EFIELD sensor on Dragonfly. Europlanet Science Congress. EPSC 2021, Sep 2021, Virtual Meeting, France. 10.5194/epsc2021-472 . insu-03305275

\section{HAL Id: insu-03305275 \\ https://hal-insu.archives-ouvertes.fr/insu-03305275}

Submitted on 28 Jul 2021

HAL is a multi-disciplinary open access archive for the deposit and dissemination of scientific research documents, whether they are published or not. The documents may come from teaching and research institutions in France or abroad, or from public or private research centers.
L'archive ouverte pluridisciplinaire HAL, est destinée au dépôt et à la diffusion de documents scientifiques de niveau recherche, publiés ou non, émanant des établissements d'enseignement et de recherche français ou étrangers, des laboratoires publics ou privés. 


\title{
Detection of sand grains blown by Titan surface winds with the DraGMet/EFIELD sensor on Dragonfly
}

\author{
Audrey Chatain ${ }^{1}$, Alice Le Gall ${ }^{1,2}$, Michel Hamelin ${ }^{1}$, Jean-Jacques Berthelier ${ }^{1}$, Ralph D. Lorenz ${ }^{3}$, \\ Rafik Hassen-Khodja ${ }^{1}$, Jean-Pierre Lebreton ${ }^{4}$, and Grégoire Déprez ${ }^{5}$ \\ ${ }^{1}$ LATMOS, Université Paris-Saclay, UVSQ, Sorbonne Université, CNRS, Guyancourt, France (audrey.chatain @ latmos.ipsl.fr) \\ ${ }^{2}$ Institut Universitaire de France (IUF), Paris, France \\ ${ }^{3}$ Johns Hopkins Applied Physics Laboratory, Laurel, MD, USA \\ ${ }^{4} \mathrm{LPC} 2 \mathrm{E}, \mathrm{CNRS}$, Université d'Orléans, Orléans, France \\ ${ }^{5}$ European Space Research and Technology Centre (ESTEC), Noordwijk, The Netherlands
}

\section{Context}

Titan, the largest moon of Saturn, is the place in the Solar System owning the most Earth-like landscapes. Titan's dense atmosphere and cold temperatures enable a complex methane hydrological cycle that have shaped the surface, very similarly to the water cycle on Earth. Titan has another peculiar feature: a wealth of organic grains is created by photochemistry in its atmosphere and progressively deposited at its surface. Such atmospheric production of organics likely occurred on Earth before the apparition of life; that is the reason why a better understanding of the formation processes, chemical composition and physical properties of these grains is of great interest.

The Dragonfly mission has recently been selected by NASA to explore Titan's surface with a rotorcraft circa 2034 (Lorenz et al., 2018). Dragonfly will explore a region of organic sand dunes with monthly flights of a few kilometres each aiming to an impact crater named Selk. In addition to chemical analyses, Dragonfly is equipped with several sensors intended to characterize its environment. Among them, as part of the Dragonfly Geophysical and Meteorological (DraGMet) package, the EFIELD instrument will record the AC electric field at low frequencies $(\sim 5-100 \mathrm{~Hz})$.

EFIELD consists in two spherical electrodes accommodated at different locations on the rotorcraft. The main scientific objective of EFIELD is to measure Schumann Resonances on Titan. Such resonances may have been detected by the Huygens probe in 2005 (unless it was an artefact of probe motion; Lorenz and Le Gall, 2020) and would be an indication of the existence of an underground global salty ocean (Beghin et al., 2012). Another scientific objective of EFIELD is the detection and characterization of charged grains. This work is dedicated to this secondary objective.

The exploration area of Dragonfly is covered by sand grains, most likely organic in nature, maybe mixed with ice. Surface winds can sometimes put them in saltation or suspension. In the process, these organic grains are likely to get charged by friction (triboelectric effect; Méndez-Harper et al., 2017), and would then induce a perturbation on the electric field detectable by the EFIELD antennas (see Figure 1). 


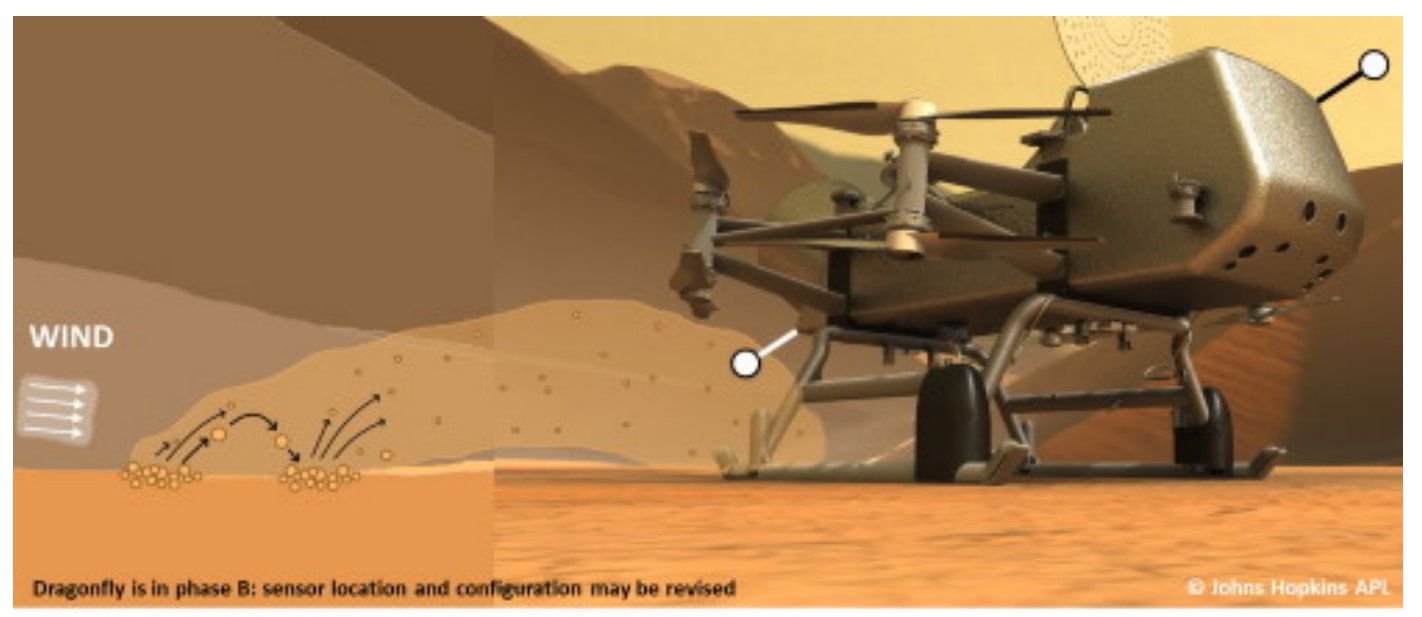

\section{Fig.1: Possible detection of sand grains blown by surface winds with EFIELD}

\section{Numerical simulation}

To estimate the significance of this perturbation and test the possibility to measure it, we have developed a numerical model that simulates the trajectory of charged particles in the probe environment, subjected to turbulent wind flows, gravity and electrostatic forces. Results show that charged particles will induce a strong measurable signal on the EFIELD spectra (see Figure 2). Particles $>100 \mu \mathrm{m}$ should be detectable with a $1 \mathrm{mV}$ resolution limit (see Figure 3 ). 

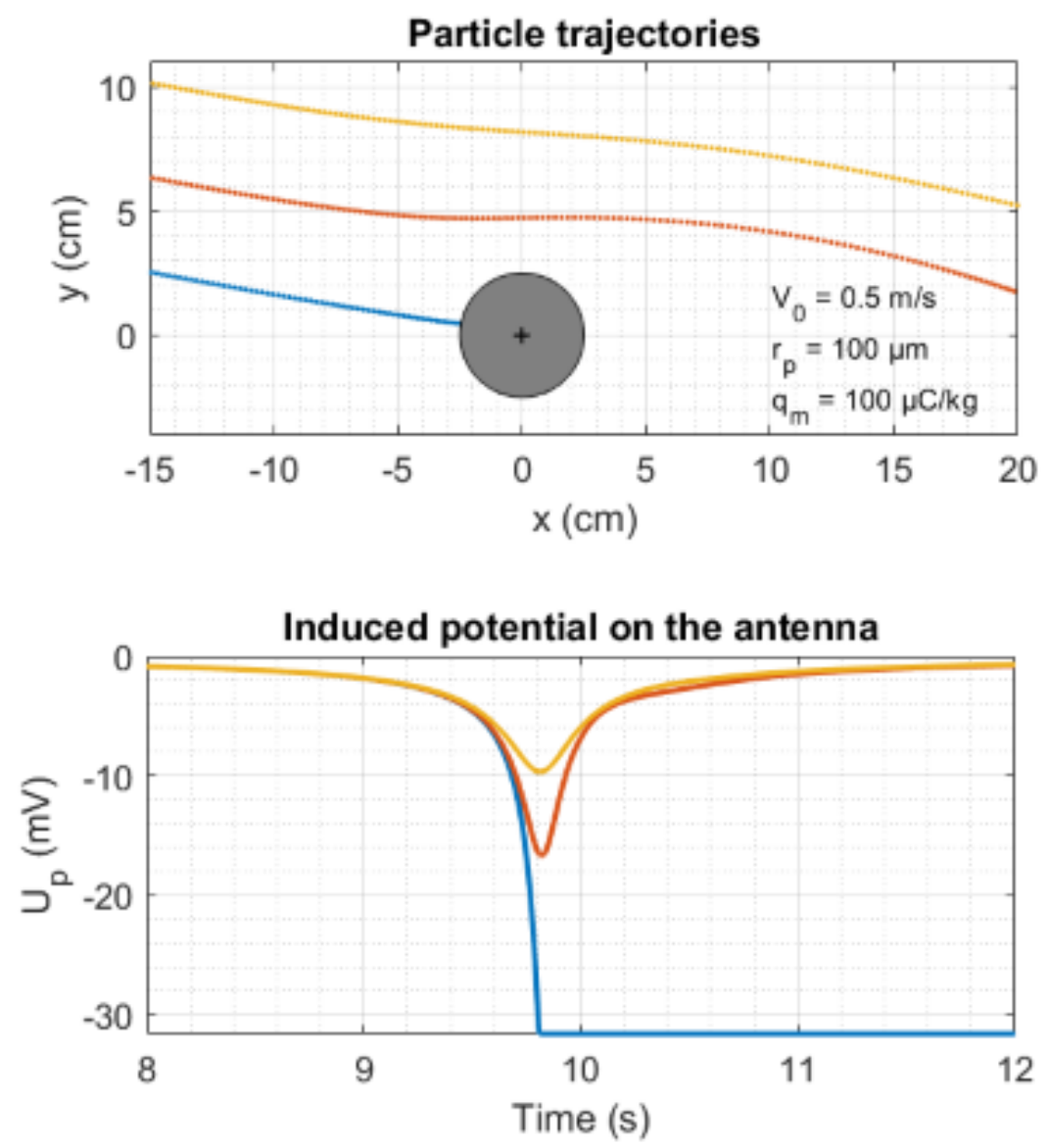

Fig.2: Simulated trajectories of particles and their induced potential on the antenna. 


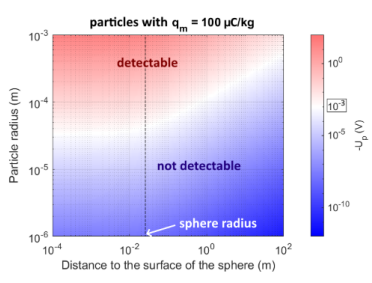

Fig.3: Amplitude of the potential induced by a charged

\section{Experimental simulation}

To test our numerical model, we built two prototypes of EFIELD antennas, adapted from previous models of Huygens/PWA AC and DC antennas (Fulchignoni et al, 2002). As analogues of sand organic grains, we used small polystyrene balls charged by friction in a rotating cylinder, itself coated with small polystyrene balls as done in (Méndez-Harper et al., 2017). Charged balls are dropped one by one to fall close to the antennas. The experiment is performed in a nearly-closed Faraday cage to avoid any electromagnetic disturbances. Examples of particle detections are given in Figure 4.

\section{Retrieval of sand grains properties}

Finally, we investigated how we could exploit these signals to derive information on the grains (number, charge, velocity). A simple approximation of particles with a linear trajectory and constant speed give a simple equation to fit the data, from which we can infer the charge/velocity ratio of the particle, as well as the minimum distance to the probe/particle velocity ratio. We first validated the approximation with simulated data in Titan's surface conditions. Figures 4 and 5 give results obtained with experiments done with 3-mm polystyrene balls. The fit results have a dispersion due to the variations in the particle charges inherent to our charging method. Nevertheless, the mean values are similar to a numerical simulation performed in the laboratory conditions. Further developments are on-going to independently measure particle charges. 

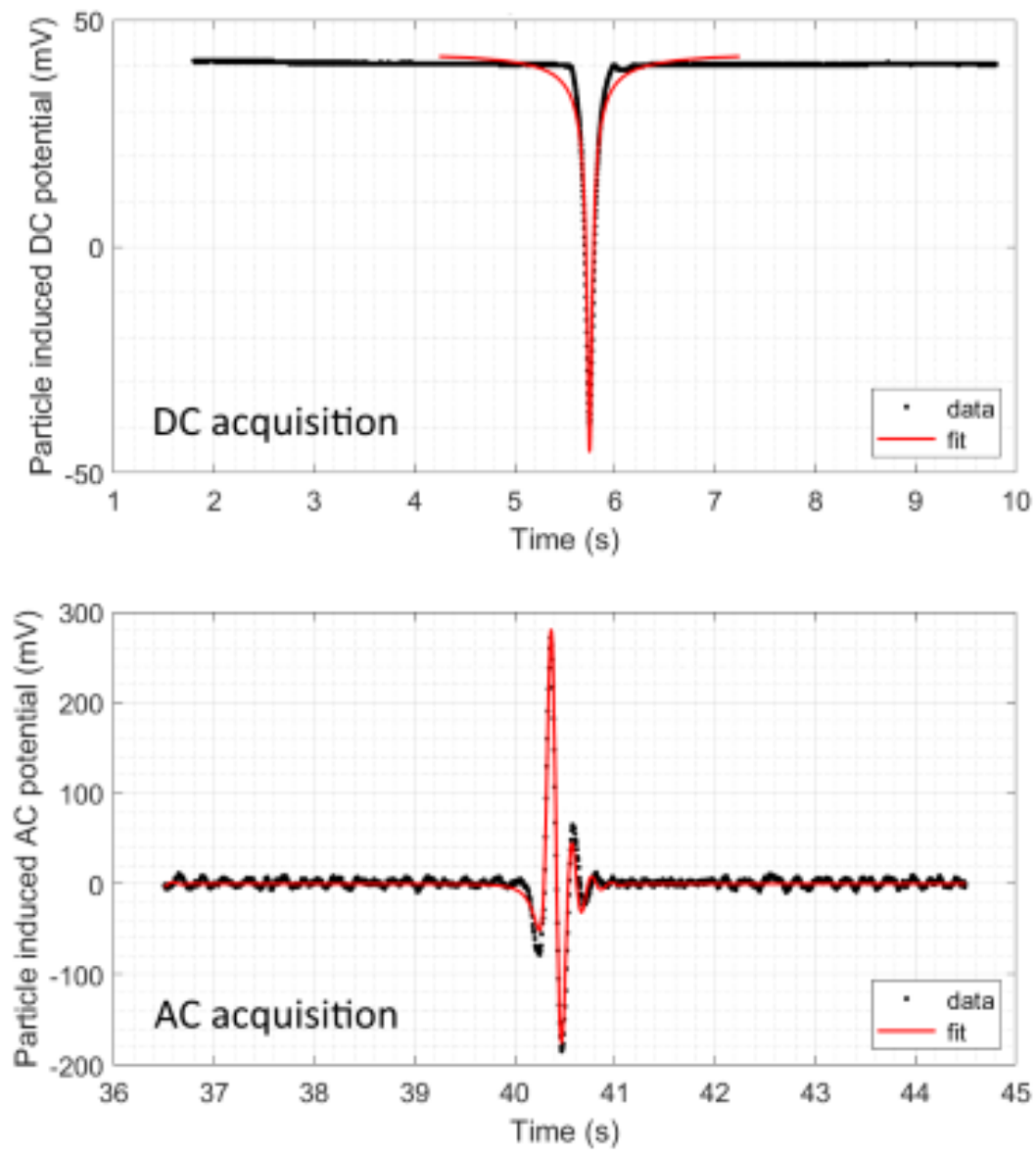

Fig.4: Examples of experimental acquisitions and their fit (for 3-mm balls). 


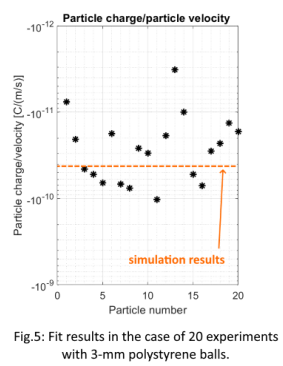

\section{Conclusion}

The EFIELD sensor on board Dragonfly will be able to investigate charged organic grains blown by winds at the surface of Titan. The signal created by the passage of a particle in particular gives access to its charge/velocity ratio. It will be possible to estimate the particle velocity from other instruments (wind sensor, cameras...), and therefore estimate the particle charge. The measurement of particle charges with the EFIELD antenna will be a valuable asset to understand the interaction between the particles and Titan surface environment (winds, saltation, friction).

\section{References}

Beghin et al., Icarus 218 (2012)

Fulchignoni et al, Space Science Reviews 104 (2002)

Lorenz et al., Johns Hopkins APL Technical Digest 34 (2018)

Lorenz and Le Gall, Icarus 351 (2020)

Méndez-Harper et al., Nature Geoscience 10 (2017) 